\title{
The Impact of Change Management on the Quality of Health Service Provided "The Moderating Role of Change Resistance": Field Study of Egyptian Private and Government Hospitals
}

\author{
Safaa Ismael Abdel-Satar, Mohamed Abdel Salam Ragheb, Abdel-Nasser Ghanem \\ Arab Academy for Science and Technology, Alexandria, Egypt \\ Email: safaahamada4@gmail.com
}

How to cite this paper: Abdel-Satar, S.I., Ragheb, M.A.S. and Ghanem, A.-N. (2022) The Impact of Change Management on the Quality of Health Service Provided "The Moderating Role of Change Resistance": Field Study of Egyptian Private and Government Hospitals. Open Access Library Journal, 9: e8354.

https://doi.org/10.4236/oalib.1108354

Received: January 30, 2022

Accepted: February 15, 2022

Published: February 18, 2022

Copyright $\odot 2022$ by author(s) and Open Access Library Inc.

This work is licensed under the Creative Commons Attribution International License (CC BY 4.0).

http://creativecommons.org/licenses/by/4.0/

\section{(c) (i) Open Access}

\begin{abstract}
The study aimed to test the effect of change management on the quality of health services by applying it to government hospitals and private hospitals through resisting change with a moderator variable. To achieve the purpose of the study, the researcher used the sampling method, where a random sample of unit (Doctors, nurses, patients) in private and government hospitals was taken, which numbered (450) individuals. Reclaim (393) forms with a recovery rate of $(87.33 \%)$. The study relied on the necessary statistical methods and tests using the SPSS 25 and AMOS25 statistical analysis programs to analyze the data. Accordingly, the study reached several results, the most important of which is the presence of significant effect from change management on the quality of health services. Based on the results of the study, the study made some recommendations, the most important of which is the need to overcome resistance to change management in order to make a successful change process, with the need to encourage medical and treatment institutions on the need to manage change to provide the best medical service provided.
\end{abstract}

\section{Subject Areas \\ Management Organization \\ Keywords \\ Organizational Change, Health Service, Quality of Services, Change \\ Resistance}




\section{Introduction}

Health services for individuals have a great importance and occupy a prominent position in the development, social and economic plans of all countries allover world [1], modern societies seek to improve the quality of health services due to their connection to human health and life, as raising the level of health for all members of society is a major goal for any country [2], and the quality of health care is key to achieving global health security, and it reflects the extent of the economic and social development of any society [3]. There is no doubt that substandard health care wastes many resources, harms the health of individuals, destroys human capital and limits productivity [4]. Good health services do not guarantee not only healthier societies, but also better human capital and a more efficient and effective economy [5].

Organizational change is one of the effective methods that can help organizations to find solutions to the problems caused by changing environment [6]. Organizational change is the mechanism that organizations rely on to confront bureaucracy, lack of development and dissatisfaction with the performance required for organizations, and it is not intended for those sudden mutations that occur for specific circumstances, whether social, economic or political, but rather the management of planned change that occurs intentionally and as a result of effort and deliberate plans by officials and development experts as a result of their awareness of a gap in the desired and actual performance in order to search for alternatives to find appropriate solutions to improve and upgrade performance [7].

Despite the most important change management and its impact on the development of organizations and hence their success and improvement of the level of their performance and the services they provide, change management often faces obstacles and difficulties represented in resisting change management, which means rejecting and obstructing the change process [8], and it can affect resistance to change which depends on adopting the concept of organizational change management, and then on the success of the change process, and accordingly the current study seeks to explore the extent of the impact of change management on improving health services in private and government hospitals in the Arab Republic of Egypt, and the extent of the impact of the existence of resistance to change on the occurrence of change, as well as the extent of the existence of difference in the degree of resistance to change among workers in private and government hospitals.

This research aims to answer the following question: "How can change management affect on the quality of health service provided on the private and public hospitals?" and also this study tries to analyze to what extent would the change resistance play a key role in change occurs? Many academic and practical implications are presented in this research, as well.

\subsection{Research Questions}

Is there a statistical relationship with a significant impact between change man- 
agement and the quality of health service provided?

- Is there a statistically significant effect of change management on tangibles of health service?

- Is there a statistically significant effect of change management on reliability of health service?

- Is there a statistically significant effect of change management on responsiveness of health service?

- Is there a statistically significant effect of change management on assurance of health service?

- Is there a statistically significant effect of change management on empathy of health service?

- Is there a statistically difference of change management on quality of health service provided due to change resistance?

- Is there a statistically differences of change management due to the type of hospital private or public?

\subsection{Research Model}

Figure 1 shows the research model of this study.

\subsection{Research Hypothesis}

Based on previous studies and a review of the study literature, the researcher noted that previous studies did not address the role of resistance to change on the failure to make change, as most of the previous studies dealt with the impact of change management on improving the service provided, whether medical or health services, banking or banking services, or educational services except These studies did not address the impact of the importance of resistance to change on the success of the desired change and improvement process, and accordingly the study model was designed to fulfill the research gap for the success of change. The study model was developed by the researcher and relied on studies (Al-Enezi, 2017), (Al-Esawy, 2018), (Farahy, 2019).

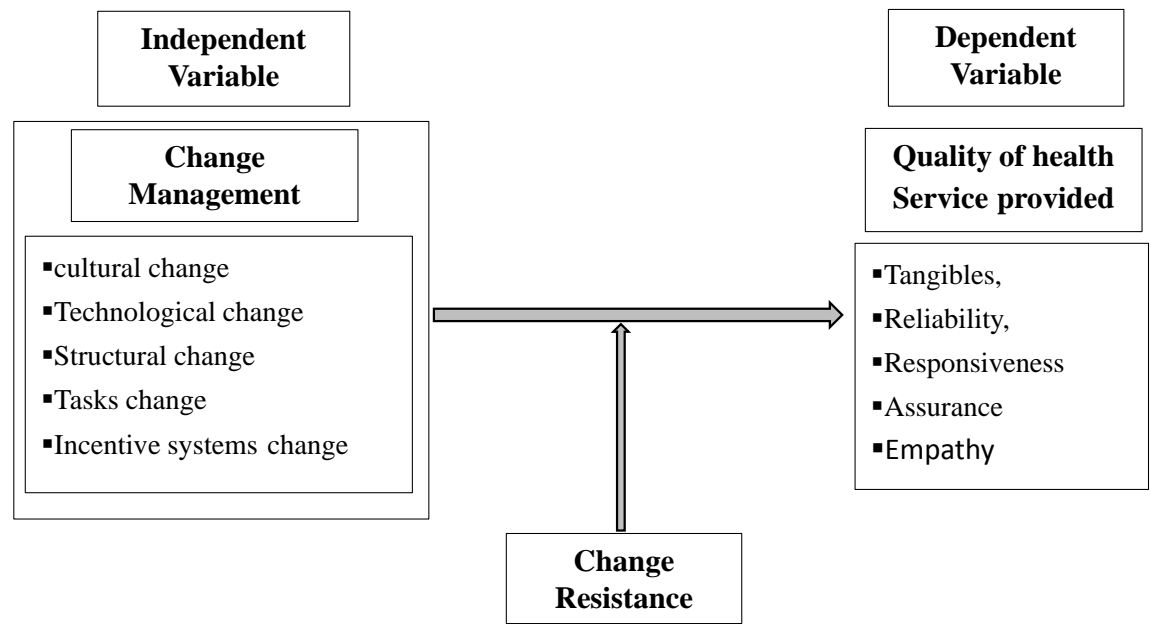

Figure 1. Research model of this study. 
In order to trying to answer the research questions, according to literature review and previous studies, the following hypothesis were developed to decide if there is a significant impact of change management on work stress:

- There is a statistically significant effect of change management on tangibles of health service.

- There is a statistically significant effect of change management on reliability of health service.

- There is a statistically significant effect of change management on responsiveness of health service.

- There is a statistically significant effect of change management on assurance of health service.

- There is a statistically significant effect of change management on empathy of health service.

- There is a statistically difference of change management on quality of health service provided due to change resistance.

- There is a statistically difference of change management due to the type of hospital private or public.

\section{Literature Review}

\subsection{Quality of Health Services}

According to the World Health Organization (WHO), the quality of health services is defined as "compliance with standards and correct performance, in a safe manner acceptable to the community, and at an acceptable cost, which leads to a change and affects the rate of disease cases and mortality, such as disability and malnutrition" [9].

The quality of the health service is measured by the availability of the five dimensions of the health service provided by hospitals or institutions, and these dimensions are represented in [10]:

\section{1) Tangibles:}

The physical elements and tangible facilities that increase the feeling of patients and beneficiaries of the services of health and treatment institutions, and increase the possibilities of their attendance and return to the same health service provider, and include the exterior of the building and the means of comfort and luxury [11].

\section{2) Reliability:}

It reflects the degree of confidence of the beneficiaries of medical services in the ability of the health institution and the extent of its dependence on it to obtain the medical services that it expects [12].

\section{3) Responsiveness:}

The degree to which the needs of all patients are met equally without discrimination, and they receive prompt care by health institution workers with different medical and administrative staff with good treatment and cooperation, with appropriate waiting periods [13]. 


\section{4) Assurance:}

The patient feels comfortable and reassured when dealing with the health institution and its various medical and administrative staff, in addition to providing the appropriate medical supplies related to the health field, which ensures the provision of high quality health services [14].

\section{5) Empathy:}

The degree of care and special care for the beneficiary, paying attention to his health complaint and working to find solutions to it in humane and upscale ways [15].

\subsection{Change Management}

The process of transforming the organization by applying a holistic, practical, gradual approach from the current reality to the reality to be reached through the development of business and behavior by following practical methods to enhance the management of the change to be brought about. Or they are organized efforts aimed at improving the organization's capabilities to make decisions, solve problems and create parallel relationships between it and the environment through the use of behavioral sciences [16].

The dimensions of change management are represented in managing change in culture, managing change in organizational structure, managing change in technology, managing change in tasks and changing incentive systems [17]:

\section{1) Changing the culture:}

Changing the values, beliefs and methods of dealing and treatment that are issued by the employees, which are the components that form the personality of the organization, and touched by the dealers and the society in which that organization resides, whether inside or outside official working hours [18].

\section{2) Changing the organizational structure:}

Change management includes all administrative divisions or administrative units or divisions of departments, and the relationships of authority and responsibility in the organization [19].

\section{3) Technological change:}

Change management includes the equipment and new ways and means of business, the use of advanced technologies in order to maintain the lead or stay in the competition to ensure the improvement of the performance of workers through technical means to facilitate business and speed up the completion and upgrading of the services provided [20].

\section{4) Changing tasks:}

Change management includes everything related to job design and determining the way work is performed, the type of activities and tasks, as well as the size of responsibilities, powers and tools, the nature of relationships in the job and the shape of the surrounding working conditions [21].

5) Incentive Systems:

Change management includes everything that the organization grants to its 
employees, including basic wages, salary, incentive bonuses, periodic or exceptional bonuses, commissions, promotions, profit participation, or the like, whether material or moral, in a way that guarantees workers an appropriate standard of living and meeting the material burdens of life [22].

\section{Research Methodology}

The study adopted a descriptive analytical method, the questionnaire was study's main tool for collecting data; where (450) forms were distributed, and (393) questionnaires were retrieved for analysis, the rate was (87.33\%) of the distributed questionnaires. Analyzing data was conducted using a set of statistical methods including exploratory factor analysis, means, standard deviation,, multiple linear regression, Structural equation Modeling (SEM) and (Path Analysis) using SPSS-V25 and AMOS-V25.

\subsection{Study Tool}

In order to collect data, a researcher-made questionnaire based on literature review and previous studies, questionnaires have three sections: Change management, quality of health service and basic respondent demographic data.

cultural change management - change of organizational structure - management Technological change - change of tasks - change of wage and incentive systems.

The (39) item scale of Change management is based on (Al-Enezi, 2017) study. There were (7) items measuring cultural change management, (9) items measuring, change of organizational structure, (8) items measuring, Technological change, (8) items measuring change of tasks and (7) items measuring, incentive systems.

The 40-item scale of quality of the health service section is based on (Al-Esawy, 2018). There were (9) items measuring Tangibles, (8) items measuring Reliability, (7) items measuring Responsiveness, (7) items measuring Assurance, and (9) items measuring Empathy.

The 14-item scale of change resistance section is based on (Farahy, 2019) study. Responses to all items scales were anchored on a five (5) point Likert scale for each statement which ranges from (5) "full agreement," (4) for "agree," (3) for "neutral," (2) for "disagree," and (1) for "full disagreement."

\subsection{Evaluating Reliability}

The reliability of the study questionnaire was verified by Cronbach's Alpha coefficient, and the results showed the Cronbach Alpha coefficient (98.3\%) which is a statistically acceptable level as long as it is greater than (0.7) (Table 1) [23].

\subsection{Evaluating Validity}

In this research, all scales for measuring study variables constructs have content validity since the development of these measurement items was based mainly on 
Table 1. Questionnaire reliability.

\begin{tabular}{lcccc}
\hline & Variable & Dimension & Item No & $\begin{array}{c}\text { Cronbach Alpha } \\
\text { coefficient }\end{array}$ \\
\hline 1 & & cultural change & 7 & 0.884 \\
2 & Independent & Technological change & 9 & 0.912 \\
3 & variable Change & Structural change & 8 & 0.938 \\
4 & management & Tasks change & 8 & 0.987 \\
5 & & Incentive systems change & 7 & 0.883 \\
& & & 39 & 0.970 \\
\hline 6 & & Tangibles, & 9 & 0.910 \\
7 & Dependent & Reliability, & 8 & 0.880 \\
8 & Variable quality & Responsiveness & 7 & 0.854 \\
9 & of health service & Assurance & 7 & 0.947 \\
10 & & Empathy & 9 & 0.948 \\
& & & 40 & 0.969 \\
\hline 11 & & & 14 & 0.935 \\
& & Change Resistance Moderator & 0.983 \\
\hline
\end{tabular}

an extensive review of the literature, all questionnaire items judged by arbitrators with experience in academic and professional field.

The researcher verified the validity of the questionnaire through convergent validity, where the Kaiser-Meyer-Olkin (KMO) indicators were calculated, the Average Variance Extracted (AVE) in addition to the regression weights for the Standardized Regression Weights (SRW) items. In order to achieve asymptotic validity, the values of (KMO), (AVE), (SRW) must be greater than or equal to 0.5 (Table 2).

\section{Results}

\subsection{Description of the Demographic Characteristics of the Study Sample}

The demographic characteristics of the study sample members were analyzed in terms of (gender, age, marital status, academic qualification, practical experience in the current job, administrative level) and the results were as follows (Table 3):

The ratio of males to females is almost equal, at a rate of (52.16\%) and (47.84\%), respectively, and that doctors are the most members of the researched sample with a percentage of nearly half (49.36\%), most of the sample members have an average experience of less than 10 years.

\subsection{Hypothesis Testing}

\subsubsection{First Major Hypothesis Test}

The first main hypothesis of the study was: 
Table 2. Conducting KMO and AVE indices for validity.

\begin{tabular}{lcccc}
\hline & Variable & Dimension & KMO & AVE \\
\hline 1 & & cultural change & 0.842 & 0.556 \\
2 & & Technological change & 0.823 & 0.541 \\
3 & Independent variable & Structural change & 0.829 & 0.639 \\
4 & Change management & Tasks change & 0.814 & 0.529 \\
5 & & Incentive systems change & 0.709 & 0.587 \\
\hline 6 & & Tangibles, & 0.760 & 0.538 \\
7 & Dependent & Reliability, & 0.780 & 0.559 \\
8 & Variable quality of & Responsiveness & 0.801 & 0.689 \\
9 & health service & Assurance & 0.814 & 0.739 \\
10 & & Empathy & 0.864 & 0.679 \\
\hline 11 & & Change Resistance Moderator & $\mathbf{0 . 7 7 2}$ & $\mathbf{0 . 5 1 2}$ \\
\hline
\end{tabular}

Table 3. Demographic characteristics of the study sample.

\begin{tabular}{|c|c|c|c|c|}
\hline & demographic information & No & $\%$ & Total \\
\hline \multirow{2}{*}{ Gender } & Female & 188 & $47.84 \%$ & \multirow{2}{*}{293} \\
\hline & Male & 205 & $52.16 \%$ & \\
\hline \multirow{4}{*}{ الوظيفة } & Doctors & 194 & $49.36 \%$ & \multirow{4}{*}{393} \\
\hline & nurses & 96 & $24.43 \%$ & \\
\hline & Employee & 74 & $18.83 \%$ & \\
\hline & Other & 29 & $7.38 \%$ & \\
\hline \multirow{3}{*}{ المؤهل العلمي } & Moderate graduation & 18 & $4.58 \%$ & \multirow{3}{*}{393} \\
\hline & High graduation & 165 & $41.98 \%$ & \\
\hline & MBA \& DBA & 210 & $53.44 \%$ & \\
\hline \multirow{4}{*}{ Experience } & Less than 5 Years & 96 & $24.43 \%$ & \multirow{4}{*}{393} \\
\hline & Over 5 and less than 10 years & 185 & $47.07 \%$ & \\
\hline & Over 10 and less than 15 years & 74 & $18.83 \%$ & \\
\hline & Over 15 and less than 20 years & 38 & $9.67 \%$ & \\
\hline
\end{tabular}

There is a statistically significant effect of the change on the quality of health service in private and governmental hospitals in Alexandria.

To verify the previous hypothesis, the researcher tested multiple regression through "change management" as an independent variable on "health service quality" as a dependent variable (Table 4).

- The value of $(F)=314,176$, which is greater than 1.96 , with a statistical significance $=0.000$, which is less than 0.05 , which means that there is a significant statistical effect of change management on the quality of the health service. 
Table 4. Multiple regression effect of the change on the quality of health service.

\begin{tabular}{|c|c|c|c|c|c|c|}
\hline & \multicolumn{2}{|c|}{$\begin{array}{l}\text { Unstandardized } \\
\text { Coefficients }\end{array}$} & \multirow{2}{*}{$\begin{array}{c}\begin{array}{c}\text { standardized } \\
\text { Coefficients }\end{array} \\
\text { Beta }\end{array}$} & \multirow[t]{2}{*}{$\mathbf{t}$} & \multirow[t]{2}{*}{ T Sig } & \multirow[t]{2}{*}{$\mathbf{F}$} \\
\hline & B & Std. Error & & & & \\
\hline (Constant) & 0.811 & 0.089 & & 9.163 & 0.000 & \multirow{2}{*}{314.176} \\
\hline cultural change & 0.120 & 0.060 & 0.134 & 1.992 & 0.047 & \\
\hline Technological change & 0.077 & 0.087 & 0.084 & 0.883 & 0.378 & F Sig \\
\hline Structural change & 0.233 & 0.084 & 0.251 & 2.770 & 0.006 & \\
\hline Tasks change & 0.264 & 0.089 & 0.290 & 2.971 & 0.003 & 0.000 \\
\hline \multirow[t]{2}{*}{$\begin{array}{c}\text { Incentive systems } \\
\text { change }\end{array}$} & 0.722 & 0.058 & 0.809 & 12.354 & 0.000 & \\
\hline & $\mathbf{R}$ & 0.896 & R Square & 0.802 & $\begin{array}{l}\text { Adjusted } \\
\text { R Square }\end{array}$ & 0.800 \\
\hline
\end{tabular}

- The value of the coefficient $(t)$ for the dimension (management of cultural change $)=1.992$, which is greater than 1.96 , with a value of statistical significance $=0.047$, which is less than 0.05 , which means that there is a significant statistical effect from the dimension (management of cultural change) on the quality of the health service.

- The value of the coefficient ( $t$ ) for the dimension (change of the organizational structure) $=0.833$ which is less than 1.96 , with a value of statistical significance $=0.378$ which is greater than 0.05 , which means that there is no significant statistical effect from the dimension (change of the organizational structure) on the quality of the health service.

- The value of the coefficient $(t)$ for the dimension (technological change management $)=2.770$, which is greater than 1.96 , with a statistical significance value $=0.006$, which is less than 0.05 , which means that there is a significant statistical effect from the dimension (technological change management) on the quality of the health service.

- The value of the coefficient ( $t$ ) for the dimension (change of tasks) $=2.971$ which is greater than 1.96 , with a statistical significance $=0.003$ which is less than 0.05 , which means that there is a significant statistical effect from the dimension (technological change management) on the quality of the health service.

- The value of the coefficient $(t)$ for the dimension (change of wages and incentives systems) $=12.354$ which is greater than 1.96 , with a value of statistical significance $=0.000$ which is less than 0.05 , which means that there is a significant statistical effect from the dimension (technological change management) on the quality of health service.

Accordingly, the regression equation can be written as follows:

Change management $=0.811+0.120$ cultural change +0.077 organizational change +0.233 technology change management +0.264 task change +0.722 pay 
and incentive systems change.

The value of the correlation coefficient $(R)=0.896$, and the value of the coefficient of determination ( $\mathrm{R}$ Square) $=0.802$. The coefficient of determination is called the coefficient of interpretation, because it means that the combined independent variables included in the model (included in the study) are (cultural change management - change of organizational structure - management Technological change - change of tasks - change of wage and incentive systems) has explained $80 \%$ of the changes that occurred to the dependent variable, which is the quality of the health service, which reflects the severity of the importance of the elements of change management in bringing about an improvement in the quality of the medical service.

\subsubsection{The Second Main Hypothesis Test}

The second main hypothesis aims to test the impact of change management on the quality of service provided, in the presence of resistance to change management among workers in government and private hospitals.

To verify the impact of change management resistance on creating change management and improving the quality of the medical service provided, the Structural equation Modeling (SEM) and Path Analysis test are used, in addition to the requirements of the model conformity indicators, through the effect of (Management of Change) on the quality of the medical service provided, and through the effect of (change management) weighted by (resistance to change management) on the quality of the medical service provided (Table 5).

The value of the impact of change management on service quality is 0.56 with a statistical significance level of 0.017 , less than 0.05 , meaning there is a significant effect of change management on service quality, while the effect of change management in the presence of change management resistance on service quality is 0.048 , with a statistical significance level of 0.311 , greater than 0.05 , That is, there is no effect of change on the quality of service in the presence of resistance to change, which means the importance of give effort to overcome resistance to change among employees.

\subsubsection{Test the Third Main Hypothesis}

The third main hypothesis aims to test the existence of statistically significant differences between workers in private hospitals and workers in government hospitals in terms of wages and incentives systems, and to verify the previous hypothesis, (wages and incentives systems) were tested for each of the workers in

Table 5. Effect of the change on the quality of health service.

\begin{tabular}{ccccccc}
\hline $\mathbf{P}$ & C.R & S.E. & Estimate & & \\
\hline 0.017 & 2.396 & 0.235 & 0.564 & quality of service & $<-$ & Change management \\
0.311 & 1.013 & 0.047 & 0.048 & quality of service & $<-$ & $\begin{array}{c}\text { Change management } \times \\
\text { Change resistance }\end{array}$ \\
\hline
\end{tabular}


private hospitals in private hospitals and workers in public hospitals using Kolmogorov-Smirnov and Shapiro-Wilk tests to determine the extent of its dependence on a normal distribution, in order to verify the correct test of the chance test (Table 6).

The Sig value of each of Kolmogorov-Smirnov and Shapiro-Wilk $=0.000$, which is less than 0.05 , which means that wages and incentives systems are not normal distributed, and accordingly the Mann-Whitney test is chosen to test the extent of There are statistically significant differences between two independent samples (Table 7).

The result of the Mann-Whitney test to determine the extent to which there are statistically significant differences between workers in private hospitals and workers in government hospitals in Alexandria in terms of the level of wage and incentive systems.

The value of the statistical significance, $\mathrm{Sig}=0.000$, which is less than 0.05 , which means that there are statistically significant differences between workers in private hospitals and workers in government hospitals in Alexandria in terms of the level of wages and incentives systems.

\subsection{Discussion}

- There is a significant statistical effect of change management on the quality of health service.

- There is a significant statistical effect from a distance (management of cultural change) on the quality of the health service.

- The absence of a statistically significant effect from a distance (changing the organizational structure) on the quality of the health service.

- There is a significant statistical effect from a distance (technological change management) on the quality of health service.

- There is a statistically significant effect from a distance (change of tasks) on the quality of the health service.

Table 6. Quality of health service normality test.

\begin{tabular}{|c|c|c|c|c|c|c|}
\hline \multicolumn{7}{|c|}{ Tests of Normality } \\
\hline \multicolumn{3}{|c|}{ Shapiro-Wilk } & \multicolumn{3}{|c|}{ Kolmogorov-Smirnov } & \\
\hline Sig. & df & Statistic & Sig. & df & Statistic & \\
\hline 0.000 & 393 & 0.722 & 0.000 & 393 & 0.374 & incentives systems \\
\hline
\end{tabular}

Table 7. Mann-Whitney test for differences between two independent samples.

\begin{tabular}{cc}
\hline & quality of health service \\
\hline Mann-Whitney U & $10,392.500$ \\
Wilcoxon W & $30,492.500$ \\
Z & -9.060 \\
Sig. & 0.000
\end{tabular}


- There is a statistically significant effect from a distance (change of wages and incentives systems) on the quality of the health service.

- The change management factors that have the most impact on the quality of the health service is the change of pay and incentive systems, then the change of tasks, then the management of technological change, then the management of cultural change, and then the change of the organizational structure.

- There is a statistically significant effect of the change on the tangible aspects of the health service in private and government hospitals in Alexandria.

- There is a statistically significant effect of the change on the degree of reliability of the health service in private and government hospitals in Alexandria.

- There is a statistically significant effect of the change on the degree of health service response in private and government hospitals in Alexandria.

- There is a statistically significant effect of the change on the degree of health service guarantee in private and government hospitals in Alexandria.

- There is a statistically significant effect of the change on the degree of health service sympathy in private and government hospitals in Alexandria.

- There are statistically significant differences between workers in private hospitals and workers in government hospitals in Alexandria in terms of the level of service quality provided.

- There are statistically significant differences between workers in private hospitals and workers in government hospitals in Alexandria in terms of wages and incentives systems.

- There are no statistically significant differences between workers in private hospitals and workers in government hospitals in Alexandria in terms of resistance to change management.

- There is no effect of change on the quality of the service provided in the presence of resistance to change management among workers in government and private hospitals.

- Resistance to change management does not differ according to the difference between workers in private hospitals and those working in government hospitals.

\subsection{Recommendation}

- The necessity for organizations in general and medical and health institutions to seek to manage change in all aspects of the organization, due to the role of change management in improving the quality of the service provided in general and the health service provided in particular.

- When conducting the change management process, it is necessary to manage the change of the organizational culture in terms of values, principles and beliefs for the role of cultural change management in bringing about the change management process.

- To make a successful change, it is necessary to seek to change the elements of the organizational structure, as it is one of the main elements of change, as it 
includes the relationships of authority and responsibility, the chain of command, the subordination of authority, and the hierarchy of administrative levels. Therefore, successful change management must include the organizational structure of organizations.

- One of the fundamental elements of change management is to change the elements of technology and the infrastructure of information technology, as well as the development of devices, equipment and various technical aspects of information systems, means of communication and all elements of technology.

- The need to seek to change the tasks of organizations in order for change management to become effective, as change management must include everything related to job design and determining the method of performing work, the type of activities and tasks, as well as the size of responsibilities, powers and tools, the nature of relationships in the job and the form of surrounding working conditions, as well as It includes managing change in duties, actions, or activities, or integrating activities with each other.

- Wages and incentives systems play an important and main role in arousing the enthusiasm and motivation of workers in all organizations, and wages and incentives systems are the most influential change management factors on the quality of health service, and therefore effective change management must include changing wages and incentives systems, which has a great impact on motivating and stimulating Employee motivation.

\section{Conclusions}

The study aimed to highlight the role of resistance to change in the impact of change management on the quality of the health service provided. The study also aimed to compare wage and incentive systems between workers in private and government hospitals, as well as comparison between resistance to change among workers in private and government hospitals, and the study concluded that change resistance is very important to make successful change, managers should pay attention to how to overcome change resistance.

The study also concluded that there are significant differences between wage and incentive systems among workers in private and government hospitals.

\section{Conflicts of Interest}

The authors declare no conflicts of interest.

\section{References}

[1] Wanza, L. and Nkuraru, J.K. (2016) Influence of Change Management on Employee Performance: A Case of University of Eldoret, Kenya. International Journal of Business and Social Science, 7, 190-199.

[2] Al-Damen, R. (2017) Health Care Service Quality and Its Impact on Patient Satisfaction "Case of Al-Bashir Hospital". International Journal of Business and Man- 
agement, 12, 136-152. https://doi.org/10.5539/ijbm.v12n9p136

[3] Amin, M. and Nasharuddin, S. (2013) Hospital Service Quality and Its Effects on Patient Satisfaction and Behavioural Intention. Clinical Governance: An International Journal, 18, 238-254. https://doi.org/10.1108/CGIJ-05-2012-0016

[4] Daniel, C. (2019) Effects of Change Management on the Performance of Firms in Nigeria. International Journal of Advances in Scientific Research and Engineering, 5, 59-64. https://doi.org/10.31695/IJASRE.2019.33065

[5] Manzoor, F., Wei, L., Hussain, A., Asif, M. and Shah, S.I.A. (2019) Patient Satisfaction with Health Care Services: An Application of Physician's Behavior as a Moderator. International Journal of Environmental Research and Public Health, 16, Article No. 3318. https://doi.org/10.3390/ijerph16183318

[6] Wahyuni, N. and Triatmanto, B. (2020) The Effect of the Organizational Change on Company Performance Mediated by Changes in Management Accounting Practices. Accounting, 6, 581-588. https://doi.org/10.5267/j.ac.2020.4.002

[7] Zeeshan Ahmed, K., Ur Rehman, Z., Asad, A., Amjad Bilal, M., Hussain, N. (2015) The Impact of Organizational Change on the Employee's Performance in the Banking Sector of Pakistan. M.Phil. Scholars, (Business Administration) National College of Business Administration \& Economics, Multan.

[8] Okeke, M.-M., Oboreh, J.C., Nebolisa, O. and Esione, U.O. and Chukwuemeka, O. (2019) Change Management and Organizational Performance in Selected Manufacturing Companies in Anambra State, Nigeria. The International Journal of Social Sciences and Humanities Invention, 6, 5437-5445.

https://doi.org/10.18535/ijsshi/v6i5.06

[9] Cooper, D. (2004) Organizational Change: From Public to Private Sector-A UK Based Reflective Case Study. The Journal of American Academy of Business, 5, 474-480.

[10] Abdelazyz, E.E.R. (2020) The Impact of Employees' Resistance to Change on Implementing E-Government Systems: An Empirical Study in Egypt. The Electronic Journal of Information Systems in Developing Countries, 86, Article ID: e12139.

[11] Andrews, J., Cameron, H. and Harris, M. (2008) All Change? Managers' Experience of Organizational Change in Theory and Practice. Journal of Organizational Change Management, 21, 300-314. https://doi.org/10.1108/09534810810874796

[12] Eisenstat, R., Spector, B. and Beer, M. (2009) Why Change Programs Does Not Produce Change? Harvard Business Review, No. 1, 86.

[13] Cisco, A. (2004) Change Management: Best Practices White Paper. Cisco, 1-13.

[14] Fløvik, L., Knardahl, S. and Christensen, J.O. (2016) The Effect of Organizational Changes on the Psychosocial Work Environment: Changes in Psychological and Social Working Conditions Following Organizational Changes. Frontiers in Psychology, 10, Article No. 2845. https://doi.org/10.3389/fpsyg.2019.02845

[15] Bhaskar, Uday, Bhal, Kanika. (2003) Ethical Issues in Change Management: An Empirical Study. Journal of Human Values, 9, 19-27. https://doi.org/10.1177/097168580300900103

[16] Baulcomb, J.S. (2003) Management of Change through Force Field Analysis. Journal of Nursing Management, 11, 275-280. https://doi.org/10.1046/j.1365-2834.2003.00401.x

[17] Sengupta, N. and Bhattacharya, M.S. (2006) Managing Change in Organizations. Prentice-Hall of India Private Limited, New Delhi.

[18] Roshnee Ramsaran-Fowdar, R. (2008) The Relative Importance of Service Dimen- 
sions in a Healthcar Setting. International Journal of Health Care Quality Assurance, 21, 104-124. https://doi.org/10.1108/09526860810841192

[19] Cooper, H., Hedges, L.V. and Valentine, J.C. (Eds.) (2019) The Handbook of Research Synthesis and Meta-Analysis. Russell Sage Foundation, New York. https://doi.org/10.7758/9781610448864

[20] Harteloh, P.P.M. (2003) The Meaning of Quality in Health Care: A Conceptual Analysis. Health Care Analysis, 11, 259-267. https://doi.org/10.1023/B:HCAN.0000005497.53458.ef

[21] Sum Brook, S. and Stewart, J. (2000) Factors Influencing Learning in European Learning Oriented Organizations. Journal of European Industrial and Training, 24, 209-219. https://doi.org/10.1108/03090590010321179

[22] Buoy, L. (2002) Employees' Perceptions as 'Recipients' of Change: A Case Study. Doctoral Thesis, Curtin University of Technology, Graduate School of Business, Perth.

[23] Hair, J.F., Risher, J.J., Sarstedt, M. and Ringle, C.M. (2019) When to use and how to report the results of PLS-SEM. European Business Review, 31, 2-24.

https://doi.org/10.1108/EBR-11-2018-0203 